\title{
People's Subjective Estimation of Fire Growth: An Experimental Study of Young Adults
}

\author{
KARL FRIDOLF, and DANIEL NILSSON \\ Department of Fire Safety Engineering and Systems Safety \\ Lund University \\ Box 118, SE-221 00 Lund, Sweden
}

\begin{abstract}
An experiment was carried out to examine the subjective estimation of fire growth for young adults and their perceived ability to extinguish fires. In the experiment, participants filled out a questionnaire consisting of two parts. The first part involved prediction of fire growth, and the participants were asked to estimate the times between different stages of fires. The second part involved estimation of the ability to extinguish different fires, and the participants were asked about their ability to extinguish the fires with a portable foam extinguisher. The results suggest that young adults are not very good at predicting fire growth, or the seriousness of a fire. There is a great variation in the estimations of the time lapsed between different stages of a fire, which means that the heat release rate of the fire often is greatly over- or underestimated. In predicting fire growth, no differences could be found between males and females or people with previous experience of fires. In addition, a great proportion of the test participants believed that a fire was too large to extinguish with a portable foam extinguisher when it in fact was not.
\end{abstract}

KEYWORDS: human behaviour, human factors, fire growth, subjective estimation, extinguishment.

\section{INTRODUCTION}

Predicting fire growth is a difficult task, even for fire safety experts. Nevertheless, a person facing a real fire must be able to do this with some level of accuracy if he/she is to arrive at an appropriate decision on what action to take, e.g., to fight the fire or to evacuate. Previous fires, such as the Stardust Club fire [1-4], the Beverly Hills Supper Club fire $[5,6]$ and the Bradford Football Stadium fire $[4,7,8]$ do, however, suggest that people faced with a growing fire situation have difficulty in defining its severity, especially in its early stages. The common feature of these fires is that they occurred in public places, i.e., in assemblies. Furthermore, the people occupying these types of buildings comprise mainly a young age group.

The Stardust Club fire occurred on 14 February 1981 in a nightclub in the North Dublin suburb of Artane. Forty eight people were killed and 182 people were seriously injured in the fire, which was most likely started deliberately by one of the guests. The victims were mainly young people in the ages $18-25$. It is clear from witness reports that many of the occupants watched the growing fire and the extinguishing attempts by others with interest, and that they made no attempt to leave until it was too late. This is illustrated by a statement in the report of the Tribunal Inquiry [1]:

"As he turned to leave the alcove, he also saw that people were standing in front of the alcove looking at him and the other doormen fighting the fire and he shouted to them to get the hell out of there." (p.2.48)

Similar observations were made in the Beverly Hills Supper Club fire in Southgate, Kentucky, which occurred on 28 May 1977. The fire claimed the lives of 165 people and around 70 people were injured. In Swartz's [6] analysis of the witness statements, he concludes that the occupants felt safe not only before being notified about the fire, but also after. Among other things, he states that [6]:

"Staff and patrons alike underestimated the severity of the emergency in almost every case, right up until the last seconds, or even until they were outside the building and looked back at the fire." (p. 73)

The fact that people have problems estimating the severity of a fire is not unique to fires at nightclubs. On 11 May 1982, a fire broke out during a match at the Bradford Football Stadium killing 56 people and injuring over 265. People in the stand affected by the fire were slow to begin moving to safety, and Sime [8] concludes that the crowd underestimated the initially small fire, which eventually developed to involve the entire wooden stand. 
Human behaviour in fire is the result of a decision-making process involving recognition and interpretation of physical fire cues and variables in the environment which influence occupant actions [9-12]. In addition, there are factors that influence each phase of the decision-making process, e.g., factors that influence the perception of the fire cues, the interpretation of the situation and the risk, and the decision about what action to take $[11,12]$.

One example of a factor is gender. Females, for instance, are more likely to perceive a fire, as well as to define the fire, as a risk [12]. Another example is visual access to the fire [12-14]. Naturally, the likelihood of a fire being perceived is increased if a person can see it. However, the decision on what action to take, such as whether to evacuate, ultimately depends on the interpretation of the risk [9,15-17]. A fire must hence be interpreted as a serious risk if a person is to make an appropriate decision on what to do.

Defining a growing fire as a risk does, in turn, require that a person's subjective estimation of the fire growth agree with the actual fire growth. However, the incidents discussed above suggest that this is not the case when people are facing a fire in its initial stage, which is typically characterized by an accelerating increase in the heat release rate, i.e., an accelerating fire growth [18]. Fire safety engineers describe this accelerating growth using a mathematical expression where it is assumed that heat release rate increases with the square of time, i.e., an alpha- $\mathrm{t}^{2}$ fire. There is thus a need to study the problem in detail in order to determine if underestimations of fire growth should be expected when a person is facing a real fire.

Subjective estimation of fire growth was studied in an experiment by Canter, Powell and Booker [19], who claim that the perceived severity of the fire and the rate of growth is a critical factor in determining the time taken to initiate movement towards exits. In the experiment, seven photographs taken at different stages of a fire (the simulation of the Stardust Club fire) were shown to the participants who were then asked to estimate the difference in time between each paired combination of photographs. The photographs were shown to a total of 20 subjects, namely 10 researchers and 10 domestic or secretarial staff. The results imply that all people in the study overestimated the times between different stages of the fire, thus underestimating the fire growth.

The above discussion implies that people may not be very good at predicting fire growth. This, in combination with other factors affecting the decision-making process in a fire situation, could mean that the severity of the fire, i.e., the risk, is underestimated and hence that evacuation is delayed. The study carried out by Canter et al. [19] included a rather small sample of participants. Furthermore, technology has developed considerably since their study and today, their experiment could be performed using film sequences instead of static pictures. This means that such experiments today can be reproduced with a higher degree of realism.

The aim of the present study is to apply a new method to study people's subjective estimation of fire growth. In addition, people's perceived ability to extinguish fires with a fire extinguisher will be examined. These aspects will be studied for a population of young adults, which corresponds closely to the type of population that can be expected in many nightclubs.

\section{METHOD}

On Friday, 19 August 2005, an experiment was performed to study estimation of fire growth by young adults and their perceived ability to extinguish a fire. The experiment was carried out in the V-building at the Faculty of Engineering at Lund University, Sweden.

\section{Test Participants}

A total of 141 participants took part in the study, namely 99 men and 42 women. The age of the participants was between 19 and 35 years, and the average age was 21.7 years. All participants were newly arrived engineering students at Lund University who had been accepted to programmes in either Civil Engineering (91 participants) or Fire Safety Engineering (50 participants). The experiment was performed during orientation day, i.e., the students' first day at university. This meant that none of the participants had begun taking courses in their respective engineering disciplines, e.g., courses in Fire Safety Engineering. Eighteen participants had either worked or performed an internship at a fire station, e.g., during their military service. 


\section{Procedure}

The experiment was at one of the stations visited by the students during their tour of the V-building at the Faculty of Engineering, Lund University. The tour of the building was performed in groups of between 9 and 15 students. All students in a group took part in the experiment at the same time.

When the participants arrived they were asked to sit down at a desk in front of a white screen. They were then given general information about the study followed by specific information about the experiment procedure.

In the experiment, a questionnaire was projected, question by question, on the white screen in front of the participants. The questionnaire, which is described in greater detail below, included video sequences of fires. The participants viewed the questions on the white screen, but wrote down their answers on a paper copy of the questionnaire. The paper copy and the questionnaire displayed on the white screen were designed to be as similar as possible.

When the participants had filled out their questionnaires, they were thanked and sent off to the next station on their tour. The entire experiment took approximately 15 min to perform per group.

\section{Questionnaire}

The questionnaire used in the experiment consisted of two parts. In the first part (Part 1) the participants were asked to estimate the time difference between video sequences from different stages of a fire, i.e., to indirectly estimate the fire growth. The second part (Part 2) involved estimation of their ability to extinguish different fires with a fire extinguisher. Finally, the participants were asked to provide information about their gender and education programme. They were also asked if they had worked or performed an internship at a fire station.

\section{Part 1 - Estimation of Time Difference}

The first part of the questionnaire (Part 1) involved estimation of the time difference between video sequences. In the questionnaire, the participants were first shown a video sequence of a growing fire from time $t_{\text {start }}$ to time $t_{\text {stop. }}$. They were then shown a looped video sequence and were asked to estimate the time difference $(\Delta t)$ between the end of the first video sequence, i.e., $t_{\text {stop }}$, and the looped video sequence. The sequence that was looped was between two and three seconds long. Figure 1 shows an example of the sequence of slides that was shown to the participants on the white screen. It can be seen in Fig. 1 that the participants were asked to state the time difference $(\Delta t)$ in minutes and seconds in the provided fields. Each participant estimated two or three time differences in the study, i.e., the sequence shown in Fig. 1 was repeated once or twice.

Two fires were used in the study, namely a fire in an arrangement of popcorn (popcorn fire) and a fire in a kitchen environment (kitchen fire). The time $t_{\text {start }}$, which denotes the start of the video sequence, was set to $0 \mathrm{~s}$ and $t_{\text {stop }}$, which denotes the end of the video sequence, varied between 14 and $60 \mathrm{~s}$ (see Table 1). For the popcorn fire, $t_{\text {start }}$ was the time of ignition and for the kitchen fire $t_{\text {start }}$ was the time when flames spread from a kitchen cabinet where the fire had originated. In Table 1 it can be seen that six variants of the questionnaire was used in the study.

Table 1. The six variants (var.) of the questionnaire - Estimation of time difference $(\Delta t)$. All times are given in seconds.

\begin{tabular}{|c|c|c|c|c|c|c|c|c|c|c|c|c|}
\hline \multirow[b]{2}{*}{ Var. } & \multicolumn{4}{|c|}{ Film sequence 1} & \multicolumn{4}{|c|}{ Film sequence 2} & \multicolumn{4}{|c|}{ Film sequence 3} \\
\hline & $t_{\text {start }}$ & $t_{\text {stop }}$ & $\Delta t$ & Type & $t_{\text {start }}$ & $t_{\text {stop }}$ & $\Delta t$ & Type & $t_{\text {start }}$ & $t_{\text {stop }}$ & $\Delta t$ & Type \\
\hline 1 & 0 & 30 & 17 & popcorn & 0 & 14 & 10 & kitchen & 0 & 30 & 50 & popcorn \\
\hline 2 & 0 & 30 & 30 & popcorn & 0 & 14 & 17 & kitchen & 0 & 30 & 70 & popcorn \\
\hline 3 & 0 & 60 & 20 & popcorn & 0 & 60 & 40 & popcorn & - & - & - & - \\
\hline 4 & 0 & 30 & 50 & popcorn & 0 & 14 & 10 & kitchen & 0 & 30 & 17 & popcorn \\
\hline 5 & 0 & 30 & 70 & popcorn & 0 & 14 & 17 & kitchen & 0 & 30 & 30 & popcorn \\
\hline 6 & 0 & 60 & 40 & popcorn & 0 & 60 & 20 & popcorn & - & - & - & - \\
\hline
\end{tabular}




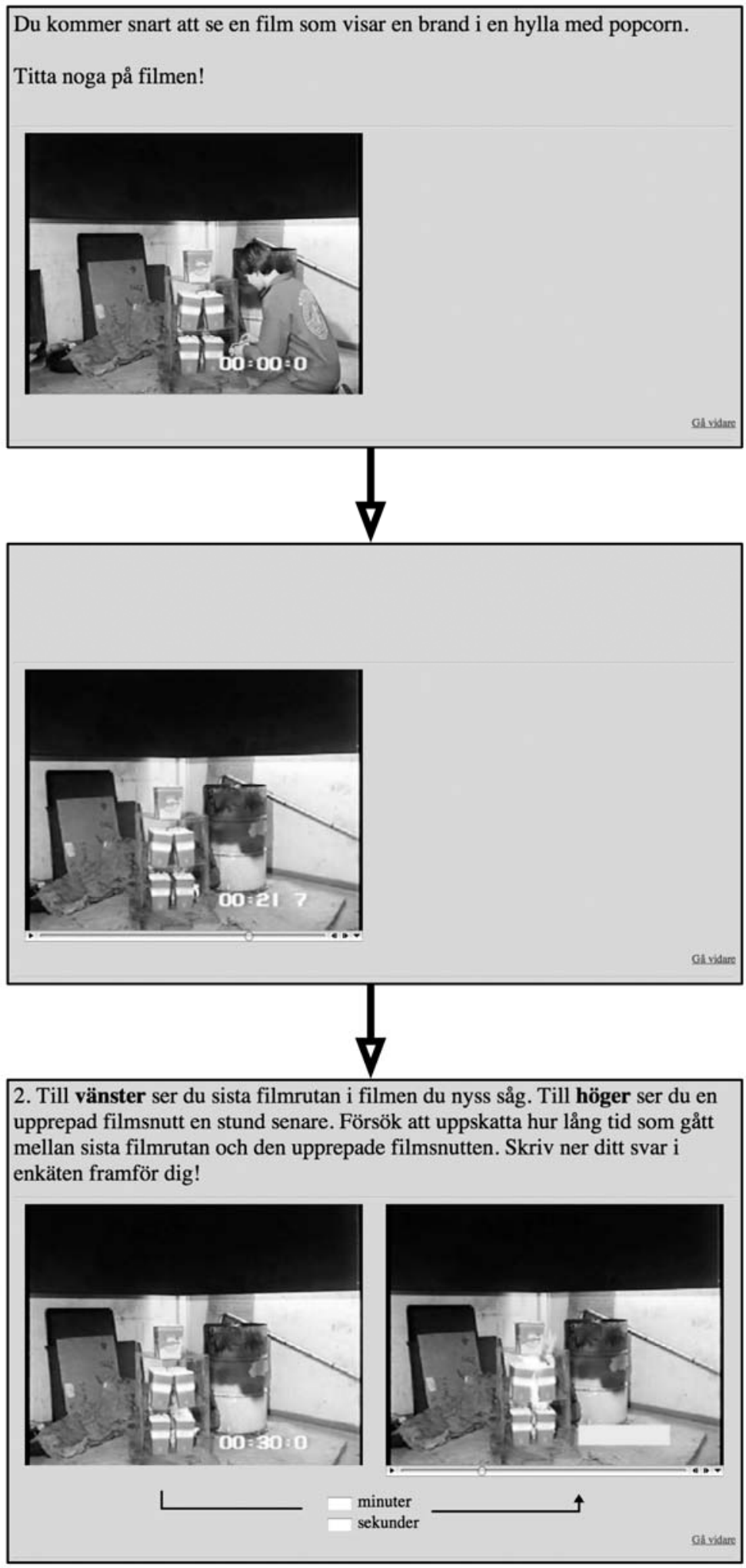

Fig. 1. An example of the sequence of slides that was shown to participants on the white screen. 
Figures 2 and 3 show images from the videos of the kitchen fire and the popcorn fire respectively. As can be seen in Fig. 2, the time was displayed in the bottom right corner of the video for the popcorn fire. For obvious reasons, however, the time was not shown in the looped video sequence. The heat release rate curve for the popcorn fire, measured by means of oxygen consumption depletion in the fire laboratory at Lund University, is shown in Fig. 4.
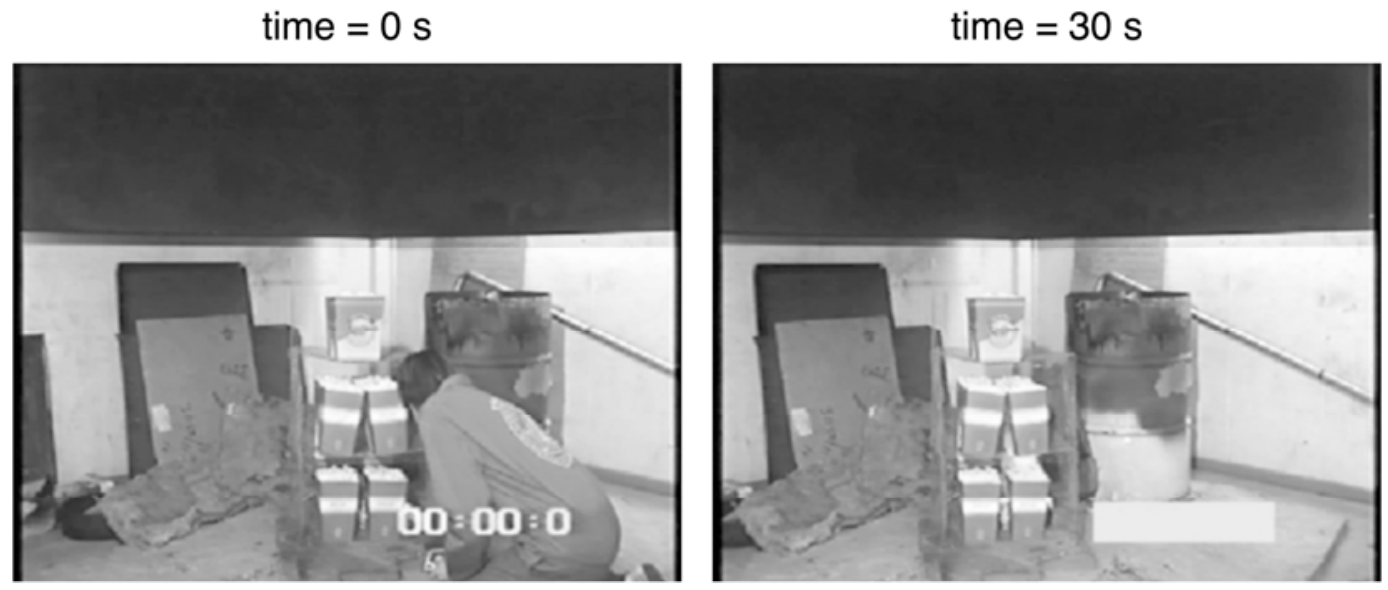

time $=47 \mathrm{~s}$

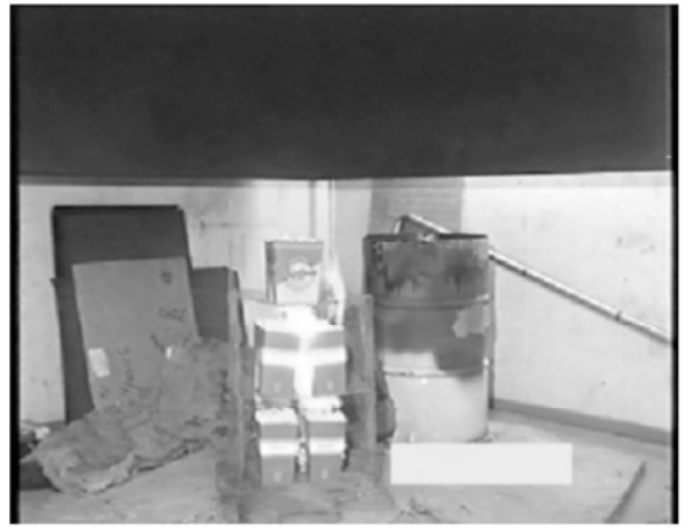

time $=80 \mathrm{~s}$

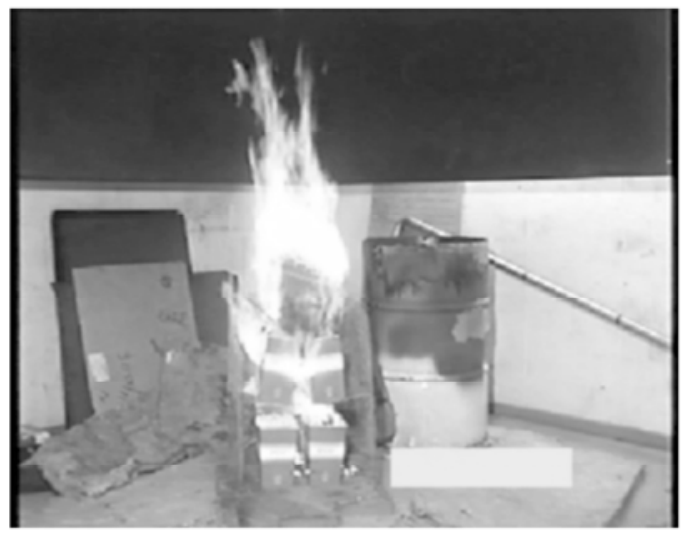

time $=60 \mathrm{~s}$

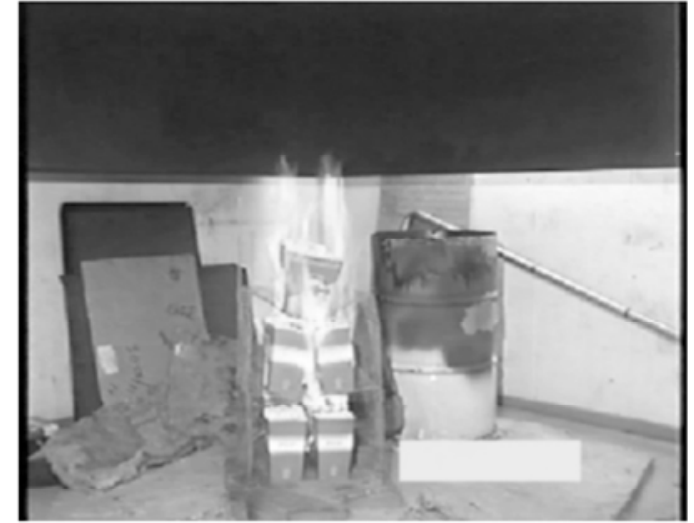

time $=100 \mathrm{~s}$

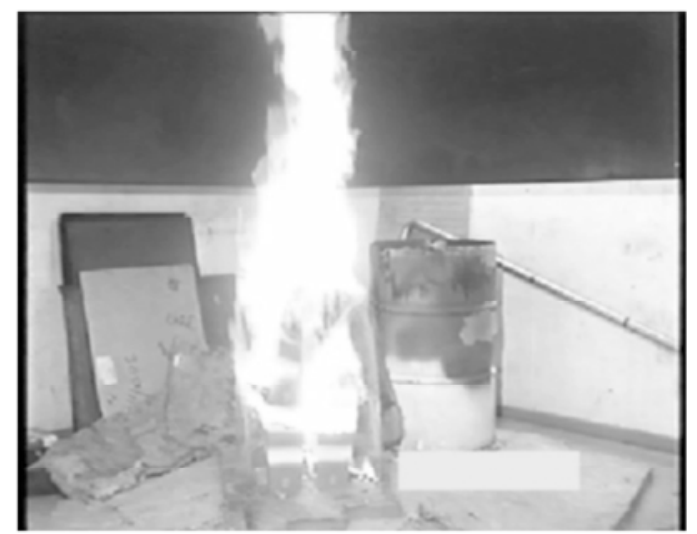

Fig. 2. Images from the video of the popcorn fire at different times after ignition. 

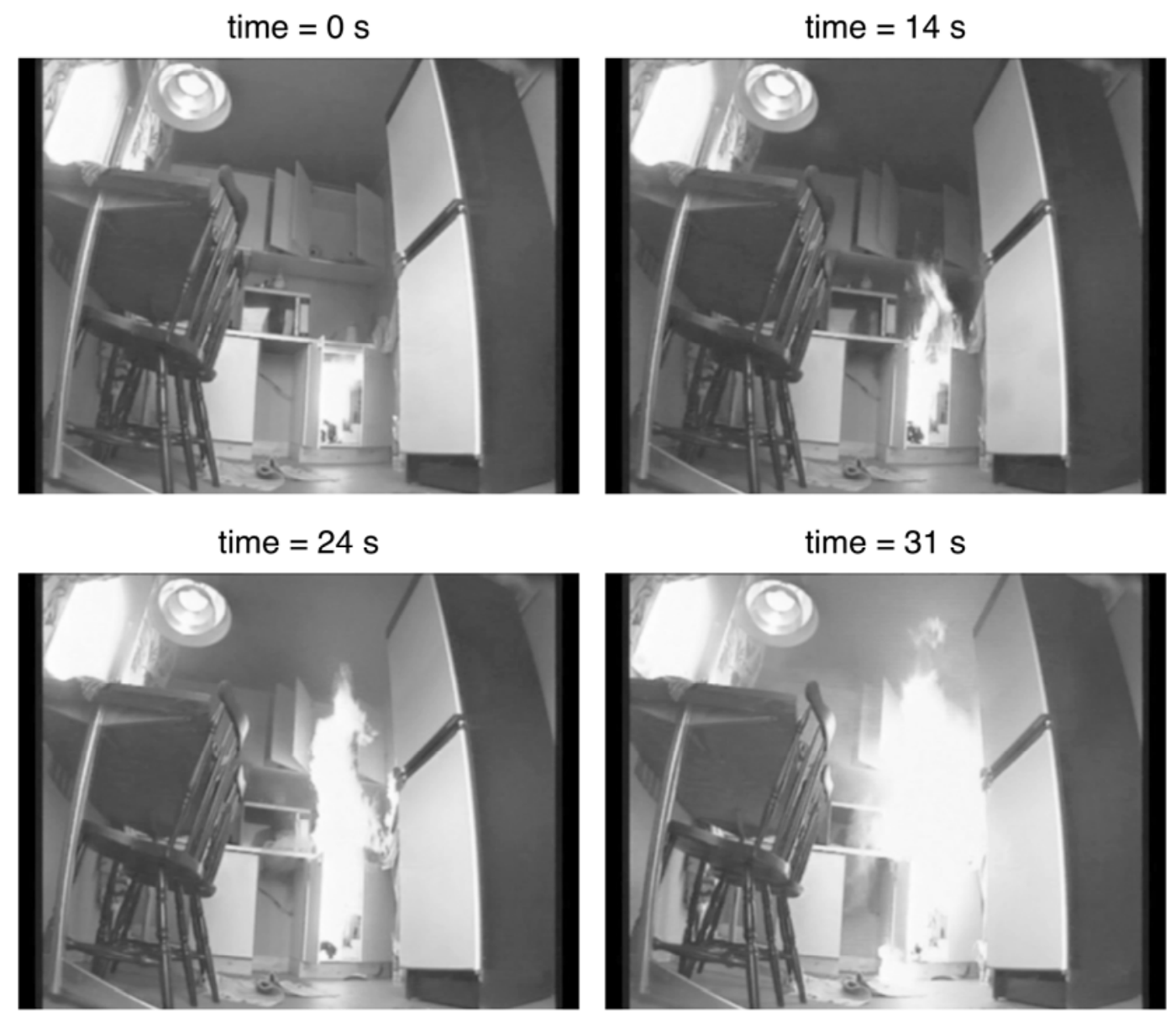

Fig. 3. Images from the video of the kitchen fire at different times after ignition.

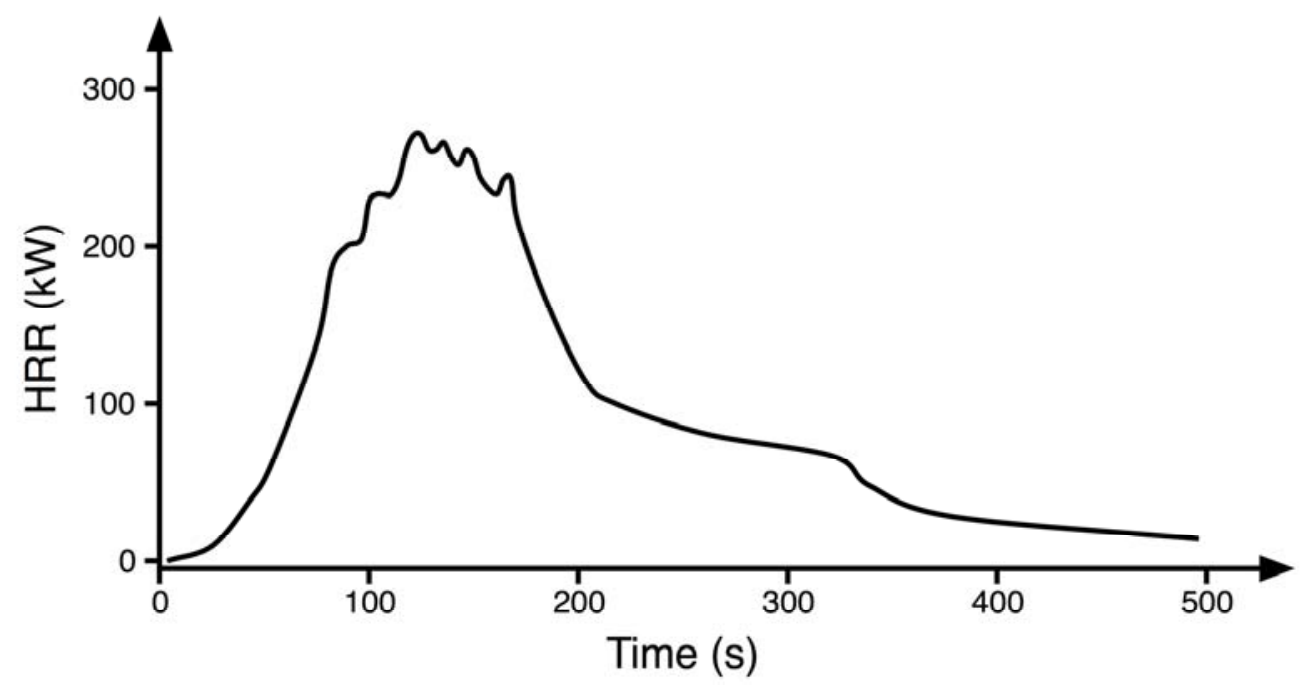

Fig. 4. Heat release rate curve for the popcorn fire.

In order to explain the questions about time differences, all participants were shown an example question, i.e., a sequence of slides similar to those in Fig. 1, before they filled out the questionnaire. In the example, a video sequence of a bus driving towards the participants was first shown. This was followed by a looped 
sequence of the bus approximately $5 \mathrm{~s}$ later. The examples were shown to all participants to ensure that everyone had understood the method of the study.

\section{Part 2 - Estimation of Ability to Extinguish Fire with a Fire Extinguisher}

In the second part of the questionnaire, the participants were asked to estimate their ability to extinguish different fires with a fire extinguisher. The participants were shown a picture of a fire extinguisher, a $9 \mathrm{~kg}$ portable foam extinguisher, together with a looped video sequence of a popcorn fire (see Fig. 5). They were then asked to estimate if they would be able to extinguish the fire with the extinguisher by answering the question: "Would you be able to extinguish the fire on the left hand side using the fire extinguisher?" (translated from Swedish). The possible reply options were: yes, no and do not know.

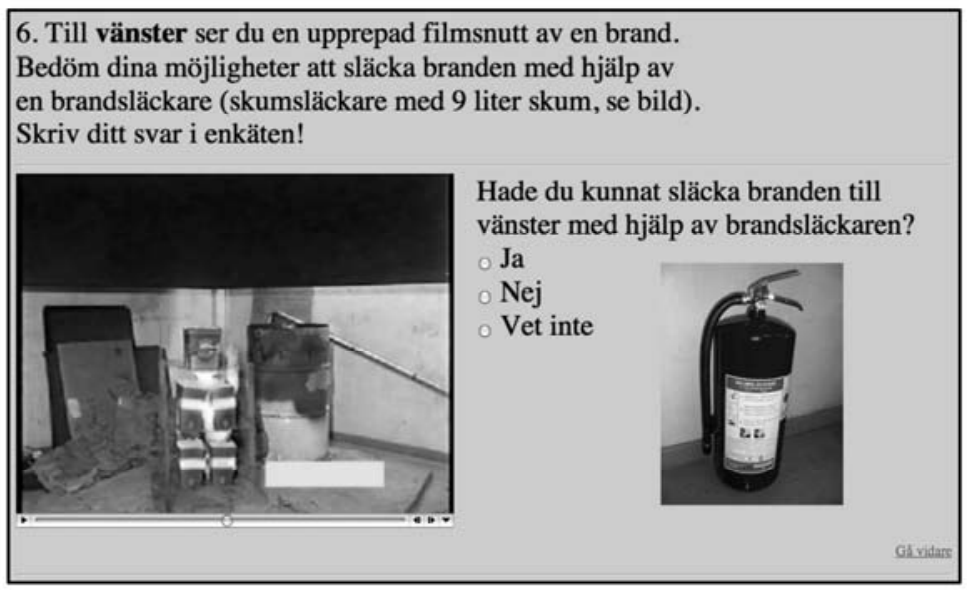

Fig. 5. The question about participants' ability to extinguish a fire with a fire extinguisher.

All of the participants were asked three times to estimate their ability to extinguish the fire. At each time, they were shown a different looped video sequence of the popcorn fire. The time after ignition (fire time) of the looped sequences is shown in Table 2 for the six variants of the questionnaire.

Table 2. The six variants (var.) of the questionnaire - Estimation of ability to extinguish fire with a fire extinguisher.

\begin{tabular}{cccc}
\hline Var. & $\begin{array}{c}\text { Fire time 1 } \\
\text { (s) }\end{array}$ & $\begin{array}{c}\text { Fire time 2 } \\
\text { (s) }\end{array}$ & $\begin{array}{c}\text { Fire time 3 } \\
\text { (s) }\end{array}$ \\
\hline 1 & 30 & 47 & 80 \\
2 & 30 & 60 & 100 \\
3 & 60 & 80 & 100 \\
4 & 30 & 80 & 47 \\
5 & 30 & 100 & 60 \\
6 & 60 & 100 & 80 \\
\hline
\end{tabular}

\section{Randomisation}

The total number of participants that took part in the study was 141. In order to minimise the effect of questionnaire design, e.g., the order of the questions, on the outcome of the study six variants of the questionnaire were used. These variants have previously been shown in Tables 1 and 2 . Table 3 shows the number of participants that filled out each of the six variants of the questionnaire. To further randomise the study the variants of the questionnaire were evenly distributed between the students of the Civil Engineering and Fire Safety Engineering programmes. 
Table 3. Number of participants who filled out the six variants (var.) of the questionnaire.

\begin{tabular}{cc}
\hline Var. & Number of participants \\
\hline 1 & 23 \\
2 & 27 \\
3 & 24 \\
4 & 22 \\
5 & 22 \\
6 & 23 \\
\hline
\end{tabular}

\section{RESULTS}

The following section presents the results from the two parts of the questionnaire. A significance level of .05 has been used in all statistical analyses.

\section{Part 1 - Estimation of Time Difference}

The results from the first part of the questionnaire reveal that there were large variations in the participants' estimation of the time difference, $\Delta t$. Figure 6 shows the estimated time, i.e., $t_{\text {stop }}$ plus the estimation of $\Delta t$, for different real times, i.e., $t_{\text {stop }}$ plus $\Delta t$. The dotted line from the origin $(0,0)$ represents a perfect estimation, i.e., the case when the estimated time equals the real time. The figure also shows the $5^{\text {th }}, 25^{\text {th }}$, $50^{\text {th }}$ (median), $75^{\text {th }}$ and $95^{\text {th }}$ percentiles for the estimated time at different real times.

It can be seen in Fig. 6 that the trend varies depending on the type of fire, i.e., for the popcorn fire versus the kitchen fire. For the popcorn fire, the participants tended to underestimate the time difference $\Delta t$, which is illustrated in Fig. 6 by the median curve lying under the dotted line (estimated time $<$ real time). Due to the fact that the fire was growing, this means that the fire growth was overestimated. It can also be seen in the figure that there are large variations, which is illustrated by the difference between the $5^{\text {th }}$ and $95^{\text {th }}$ percentile. At the time $100 \mathrm{~s}$ into the popcorn fire, the difference between the $5^{\text {th }}$ and $95^{\text {th }}$ percentile is $112 \mathrm{~s}$, i.e., almost $2 \mathrm{~min}$. For the kitchen fire, the participants tended instead to overestimate the time difference $(\Delta t)$ which is illustrated in Fig. 6 by the median curve lying above the dotted line (estimated time $>$ real time). The variation was also very large for the kitchen fire. At the time $31 \mathrm{~s}$ into the kitchen fire the difference between the $5^{\text {th }}$ and $95^{\text {th }}$ percentile is 116 s, i.e., almost 2 min.

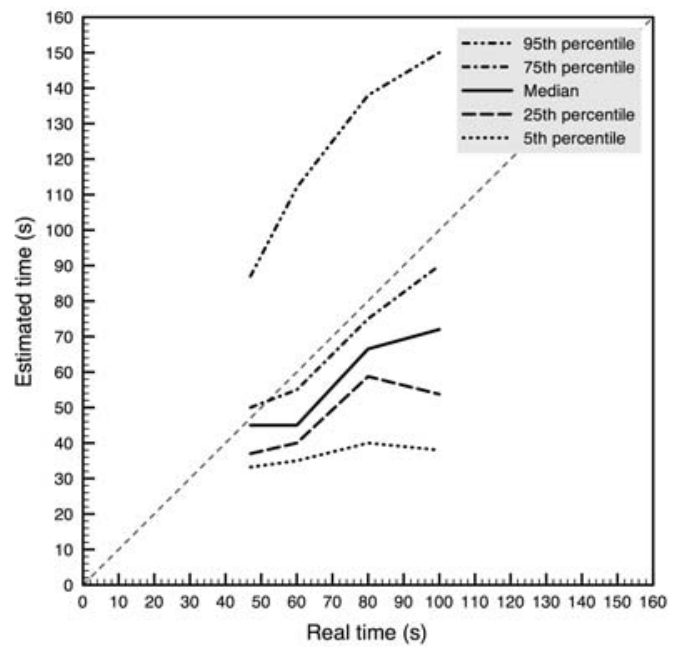

(a)

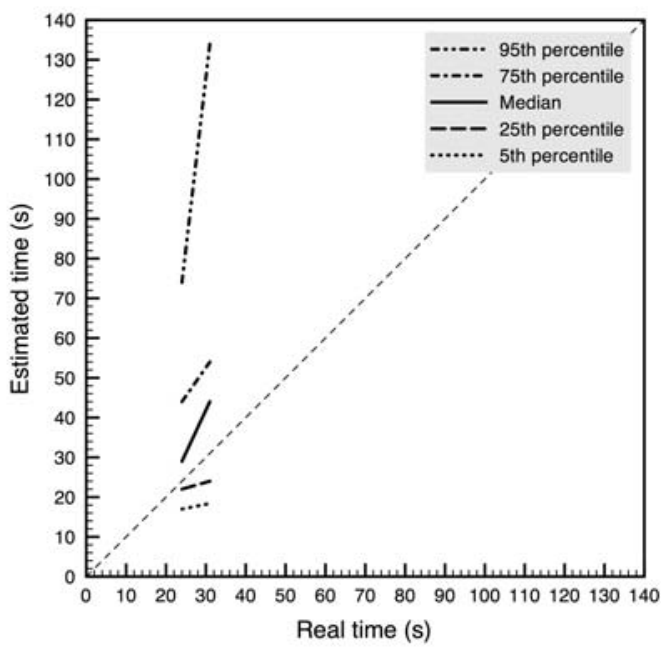

(b)

Fig. 6. Estimated time at different real times for (a) the popcorn fire and (b) kitchen fire.

In the study, participants were asked to estimate the time difference $\Delta t$ two times for the popcorn fire, and either not at all or once for the kitchen fire (see Table 1). This resulted in 282 estimations of $\Delta t$ for the popcorn fire and 94 for the kitchen fire. For the popcorn fire, the time difference was estimated exactly 
correct seven times. Of the remaining 275 estimations, i.e., estimations not exactly correct, 61 (22\%) involved overestimation of $\Delta t$ (estimated time $>$ real time). In order to test if this proportion was significantly different from $50 \%$, i.e., an equal probability of over and underestimation, a Z-test for a proportion [20] was performed. The test revealed that there was a significant difference $(Z=9.226$, $\mathrm{p}<.01$ ), which suggests that there was not an equal probability of over and underestimation of $\Delta t$ for the popcorn fire. This means that the majority of the test participants underestimated the times between different stages of the fire, thus overestimating the fire growth.

The time difference was estimated exactly correct six times for the kitchen fire. Of the remaining 88 estimations, i.e., estimations not exactly correct, $59(67 \%)$ involved overestimation of $\Delta$ t (estimated time > real time). A Z-test for a proportion [20] was performed to test if this proportion was significantly different from $50 \%$, i.e., an equal probability of over and underestimation. The test revealed that there was a significant difference $(Z=3.198, p<.01)$, which suggests that there was not an equal probability of over and underestimation of $\Delta \mathrm{t}$ for the kitchen fire. This means that the majority of the test participants overestimated the times between different stages of the fire, thus underestimating the fire growth.

A slightly higher proportion of men (25\%) than women (17\%) tended to overestimate the time difference (estimated time $>$ real time) in the study (see Table 4 ). In order to test if this difference was significant, a $\chi^{2}$ test of consistency in a $2 \times 2$ matrix [20] was performed. The test revealed no significant differences $\left(\chi^{2}=\right.$ $3.131, \mathrm{df}=1, \mathrm{p}>.05)$. The statistical analysis of differences between men and women was only performed for the popcorn fire since this was the case where most data were available.

Table 4. Number of times that the estimated time was higher and lower than the real time for the popcorn fire for men and women.

\begin{tabular}{ccc}
\hline & \multicolumn{2}{c}{ Estimated time $>$ Real time } \\
\cline { 2 - 3 } Gender & Yes & No \\
\hline Men & 47 & 144 \\
Women & 14 & 70 \\
\hline
\end{tabular}

A slightly higher proportion of participants with previous experience $(29 \%)$, i.e., who had previously worked or performed an internship at a fire station, than those without previous experience (21\%) tended to overestimate the time difference (estimated time $>$ real time) in the study (see Table 5). A $\chi^{2}$ test of consistency in a $2 \times 2$ matrix [20] was performed to test if this difference was significant. The test revealed no significant differences $\left(\chi^{2}=.949, \mathrm{df}=1, \mathrm{p}>.05\right)$. The above statistical analysis was only performed for the popcorn fire since this was the case where most data were available.

Table 5. Number of times that the estimated time was higher and lower than the real time for the popcorn fire for participants with and without previous experience of work at a fire station.

\begin{tabular}{ccc}
\hline & \multicolumn{2}{c}{ Estimated time $>$ Real time } \\
\cline { 2 - 3 } Experience & Yes & No \\
\hline Yes & 47 & 144 \\
No & 14 & 70 \\
\hline
\end{tabular}

\section{Part 2 - Estimation of ability to extinguish fire with a fire extinguisher}

The test participants' estimation of their ability to extinguish the popcorn fire at different stages is summarized in Table 6. The heat release rate for the fire was measured in a smoke exhaust hood and was corrected taking the smoke transportation time in the hood and vent into consideration. 
Table 6. The total number of answers for each stage of the fire.

\begin{tabular}{lccccc}
\hline & & \multicolumn{3}{c}{ Answer } \\
\cline { 3 - 6 } Fire time (s) & HRR (kW) & Yes & No & Do not know & $\Sigma$ \\
\hline 30 & 20 & $86(91 \%)$ & $1(1 \%)$ & $7(7 \%)$ & $94(100 \%)$ \\
47 & 55 & $43(80 \%)$ & $2(4 \%)$ & $9(17 \%)$ & $54(100 \%)$ \\
60 & 80 & $55(74 \%)$ & $7(9 \%)$ & $12(16 \%)$ & $74(100 \%)$ \\
80 & 175 & $63(55 \%)$ & $27(24 \%)$ & $24(21 \%)$ & $114(100 \%)$ \\
100 & 220 & $30(34 \%)$ & $31(36 \%)$ & $26(30 \%)$ & $87(100 \%)$ \\
\hline
\end{tabular}

As can be seen in Table 6, the majority of test participants believed that they would be able to extinguish the fire in its initial stages. However, as the fire developed and the heat release rate increased, the perceived ability to extinguish the fire decreased. In addition, the uncertainty is increased and a higher proportion of the participants were unable to specify their ability to extinguish the fire in its later stages.

The $9 \mathrm{~kg}$ foam extinguisher used in the experiment was certified according to the EN-3 ISO-standard. It was of Type $21 \mathrm{~A}$, which means that it had been tested on a fully developed wood crib fire with the dimensions $500 \times 2100 \times 546 \mathrm{~mm}(\mathrm{w} \times 1 \times \mathrm{h})$ and successfully extinguished it. The heat release rate from a fully developed wood crib fire with the above dimensions is much greater than the heat release rate from the popcorn fire, and a $9 \mathrm{~kg}$ foam extinguisher would thus be sufficient for extinguishing the fire at any of the times shown in Table 6.

\section{DISCUSSION}

One of the main contributions of the present paper is that it introduces a new method for studying people's estimation of fire growth. The proposed method is based on the approach originally developed by Canter, Powell and Booker [19], but it involves video sequences of fires instead of still images to achieve a higher degree of realism. The participants first see a video sequence of a growing fire and are then asked to estimate the time difference between the end of the video sequence and a looped video sequence of the fire at some later time in the fire development. By doing so, the participants are providing their estimate of how the fire will develop, and the results can be used to determine if people over- or under-estimate the fire growth. In this paper, the use of the new method was demonstrated for one particular population, but we hope it will be tested on more heterogeneous populations in the future.

The aim of this paper has been to study people's subjective estimation of fire growth and the perceived seriousness of fires. This was done for a population consisting of young adults, i.e., the type of population that can be expected in many nightclubs. As mentioned previously, witness accounts from previous accidents in nightclubs have suggested that people do not respond promptly when they see a growing fire, which might possibly be explained by underestimation of the fire growth. The ability of young adults to estimate the growth of a fire is therefore a highly relevant problem.

The results presented in this paper suggest that young adults are not necessarily very good at estimating how a fire will develop. This is illustrated by the large variations in the data. Poor ability to estimate fire growth can be one possible explanation for people not responding promptly when they see a growing fire. In some cases, such as the kitchen fire, this might result in the fire growth being underestimated, which corresponds to the estimated time being higher than the real time in Fig. 6. In other cases, such as the popcorn fire, the fire growth might be overestimated, which corresponds to the estimated time being lower than the real time in Fig. 6. This clearly illustrates that the estimation of fire growth is dependent on how rapidly the fire develops, since the fire development of the popcorn fire and kitchen fire are very different. A possible future study could therefore involve fires with different growth rates.

In the present paper, an attempt was made to examine how other factors, such as gender, influence the estimation of fire growth. The results suggest that men are slightly more likely to underestimate the fire growth than women. In addition, people who have worked or performed an internship at a fire station seem to be slightly more likely to underestimate fire growth than those who have not. However, none of these differences were significant in this study. This can be partly due to the small sample size (141 participants), and a more extensive and detailed future study might resolve more clearly these types of differences. 
Another aspect that should be studied in future research is how well people's estimation of fire growth can be predicted by their age.

People's ability to extinguish a fire at different stages of the fire was also examined in this paper. At all stages presented in Table 6 , the $9 \mathrm{~kg}$ foam extinguisher would have been sufficient to extinguish the fire presented to the test participants. However, a great proportion of the test participants believed that they would not have been able to extinguish the fire with the extinguisher, especially in its later stages. Although no actual statistical tests were performed, this suggests that young adults are not only poor at estimating fire growth, but also that they are not very good at predicting the seriousness of a fire. The results should be considered by fire safety engineers in the design process of buildings. The uncertainties that characterize young adults' estimation of fire growth and the perceived seriousness of a fire will effect the pre-movement time in a real fire, and should hence be considered when a building is designed.

The present study shows that young adults are not very good at estimating the fire growth, but based on the data, it is difficult to determine why this is the case. One possible explanation is that a fire growth is often accelerating, e.g., an alpha- $\mathrm{t}^{2}$ fire, and that people are poor at estimating accelerating courses of events. It is therefore recommended that future research focus on people's estimation of different types of accelerating courses of events, i.e., both fire and non-fire events. This type of study can potentially reveal explanations for the poor ability to estimate fire growth.

One important limitation of the study is that it might be difficult to estimate time in an artificial situation, i.e., when one is taking part in a study. However, a person in a real fire is likely to be confronted with the same problem, and must also in that situation make an appropriate decision of what action to take. Even if the results are not directly transferable to a real fire situation, they do imply that young adults are not very good at predicting fire growth, nor are they very good at estimating the seriousness of a fire.

\section{CONCLUSIONS}

The results presented in this paper imply that young adults in general are poor at predicting fire growth. Furthermore, the estimation of fire growth varies depending on the type of fire. The results also imply that young adults in general are poor at predicting the seriousness of a fire. In terms of heat release rate, a building occupant may therefore interpret a small fire as a large fire. This could mean that no attempt is made to extinguish the fire before evacuation is initiated.

In order for building occupants to reach an appropriate decision in a fire, e.g., to fight the fire, it is required that they can predict the growth rate and estimate the seriousness of the fire with some accuracy when they have visual access of the fire. This study suggests that people cannot do this well. The study does, however, only include a population of young adults. Future research should therefore be carried out on a larger population that includes males and females as well as young and old.

\section{REFERENCES}

[1] Keane, J.R., "Report of the Tribunal Inquiry on the Fire at the Stardust, Artane, Dublin, on the 14th February, 1981," The Stationery Office, Dublin, 1982.

[2] Morris, W., (1984) Stardust disco investigation - Some observations on the full-scale fire tests, Fire Safety Journal 7(3): 255-265, http://dx.doi.org/10.1016/0379-7112(84)90024-9

[3] Pigott, P., (1984) The fire at the stardust, Dublin: The public inquiry and its findings, Fire Safety Journal 7(3): 207-212, http://dx.doi.org/10.1016/0379-7112(84)90020-1

[4] Rasbash, R.J., Ramachandran, G., Kandola, B., Watts, J.M., and Law, M., Evaluation of fire safety, John Wiley \& Sons, Ltd, Chichester, 2004, http://dx.doi.org/10.1002/0470020083

[5] Best, R.L., (1978) Tragedy in Kentucky, Fire Journal 72(1): 27-35, 41-44.

[6] Swartz, J.A., (1979) Human Behavior in the Beverly Hills Fire, Fire Journal 73(3): 73-74, 108.

[7] Canter, D., Comber, M., and Uzzell, D.L., Football in its Place: An Environmental Psychology of Football Grounds, Routledge, London, 1989. 
[8] Sime, J., (1999) Crowd facilities, management and communications in disasters, Facilities 17(9/10): 313-324, http://dx.doi.org/10.1108/02632779910278728

[9] Bryan, J.L., "Behavioral Response to Fire and Smoke," SFPE Handbook of Fire Protection Engineering ( $\left.4^{\text {th }} e d\right)$, DiNenno P.J. (ed.), National Fire Protection Association, Quincy, MA, 2008, pp. 3/320-3/354.

[10] Canter, D., Breaux, J., and Sime, J.D., "Domestic, Multiple Occupancy, and Hospital Fires," Fires and Human Behaviour, Canter, D. (ed.), John Wiley \& Sons Ltd, Chichester, 1980, pp. 117-136.

[11] Kuligowski, E.D., "Modeling Human Behaviour during Building Fires (NIST Technical Note 1619)," National Institute of Standards and Technology, Washington, DC, 2008.

[12] Kuligowski, E.D., "The Process of Human Behaviour in Fire," $4^{\text {th }}$ International Symposium on Human Behaviour in Fire, Cambridge, 2009, pp. 627-637.

[13] Proulx, G. and Fahy, R., (1997) The Time Delay To Start Evacuation: Review Of Five Case Studies, Fire Safety Science 5: 783-794, http://dx.doi.org/10.3801/IAFSS.FSS.5-783

[14] Sime, J.D., "Visual Access Configurations: Spatial Analysis and Occupant Response Inputs to Architectural Design and Fire Engineering," $15^{\text {th }}$ International Association for PeopleEnvironment Studies Conference, Eindhoven, 1998, pp. 140-151.

[15] McConnell, N., Boyce, K., Shields, J., Galea, E., Day, R., and Hulse, L., (2010) The UK 9/11 evacuation study: Analysis of survivors' recognition and response phase in WTC1, Fire Safety Journal 45(1): 21-34, http://dx.doi.org/10.1016/j.firesaf.2009.09.001

[16] Sekizawa, A., Ebihara, M., Notake, H., Kubota, K., Nakano, M., Ohmiya, Y., and Kaneko, H., (1999) Occupants' behaviour in response to the high-rise apartments fire in Hiroshima City, Fire and Materials 23(6): 297-303, http://dx.doi.org/10.1002/(SICI)10991018(199911/12)23:6<297::AID-FAM702>3.3.CO;2-U

[17] Wood, P.G., "The Behaviour of People in Fires (No. 953)," Fire Research Station, Borehamwood, 1972.

[18] Karlsson, B., and Quintiere, J.G., Enclosure Fire Dynamics, CRC Press, Boca Raton, FL, 2000.

[19] Canter, D., Powell, J., and Booker, K., "Psychological aspects of informative fire warning systems (No. BR127)," Building Research Establishment, Watford, 1988.

[20] Gopal, K.K., 100 Statistical tests ( $3^{r d}$ ed.), Sage Publications, London, 2006. 